\title{
Meaning in Life as a Mediator of Ethnic Identity and Adjustment Among Adolescents from Latin, Asian, and European American Backgrounds
}

\author{
Lisa Kiang • Andrew J. Fuligni
}

Received: 21 September 2009/Accepted: 30 October 2009/Published online: 14 November 2009

(C) The Author(s) 2009. This article is published with open access at Springerlink.com

\begin{abstract}
Establishing a sense of life meaning is a primary facet of well-being, yet is understudied in adolescent development. Using data from 579 adolescents (53\% female) from Latin American, Asian, and European backgrounds, demographic differences in meaning in life, links with psychological and academic adjustment, and the role of meaning in explaining associations between ethnic identity and adjustment were examined. Although no generational or gender differences were found, Asian Americans reported higher search for meaning than Latin and European Americans. Presence of meaning was positively associated with self-esteem, academic adjustment, daily well-being, and ethnic belonging and exploration, whereas search for meaning was related to lower self-esteem and less stability in daily well-being. Presence of meaning mediated associations between ethnic identity and adjustment, explaining $28-52 \%$ of ethnic identity's protective effect on development. Ethnic identity thus appears to affect adjustment, in part, through its role in fostering a positive sense of meaning in adolescents' lives.
\end{abstract}

Keywords Meaning in life - Ethnic identity · Adolescents · Adjustment

L. Kiang $(\bowtie)$

Wake Forest University, P.O. Box 7778, Winston-Salem, NC 27109, USA

e-mail: KiangL@wfu.edu

\section{A. J. Fuligni}

University of California, California, LA, USA

\section{Introduction}

Many adolescents attempt to find meaning in their lives, often exploring and questioning their life purpose, their passions and motivations, and what they are meant to do with their lives and education. A key developmental task is to answer and come to terms with such questions, as the very definition of maturity involves understanding one's goals and achieving directedness and intentionality (Ryff 1989). In recent work, Ryan and Deci (2001) deconstructed primary elements of psychological well-being by differentiating hedonic well-being, a form of subjective happiness or positive mood, from eudaimonic well-being, which reflects a deeper sense of flourishing or self-actualization. Specifically, purpose or meaning in life has been identified as a fundamental dimension of eudaimonic well-being (other indices include autonomy, positive relatedness, selfacceptance, environmental mastery, personal growth; Ryff 1989, 1995), suggesting that achieving a sense of life meaning has significant implications for development.

Although precise definitions have varied, two aspects of meaning in life have been delineated (Steger et al. 2006). Presence of meaning refers to the degree to which an individual finds his or her life to be meaningful, whereas search for meaning refers to an active exploration into finding a sense of meaning. Building on this emerging work, which has been limited in its primary focus on adults from European American backgrounds, the goal of the current study was to examine how purpose and meaning, used synonymously here, play a role in the lives of adolescents from Latin, Asian, and European American backgrounds. We first examine group differences and consider whether levels of meaning vary by ethnicity, generational status, or gender. We then examine associations between adolescents' meaning in life and their 
personal, academic, and daily adjustment, and whether constructs of meaning are further linked to a sense of ethnic identification. Third, we examine whether meaning in life mediates the positive associations that are often found between ethnic identity and well-being.

Purpose and Meaning in Adolescent Development

The study of eudaimonic well-being and of meaning in life in particular is only beginning to gain popularity in the field (Damon et al. 2003). One limitation to this growing literature is the strong reliance on largely college-aged, European American samples. Indeed, there are a number of theoretical reasons to suspect that finding a sense of meaning in life is highly relevant to adolescents and, especially, to those from ethnic minority backgrounds.

A central developmental concern during adolescence revolves around establishing a sense of purpose or meaning (Damon et al. 2003). Theoretical perspectives stemming from Erikson (1968) have long suggested that adolescence is a formative period during which youth are preoccupied with defining who they are and determining what set of beliefs they should dedicate their lives to. The life meaning that materializes from such exploration and identity development then has the potential to influence adolescents' developmental trajectories, for instance, their future goals and expectations (Emmons 1999). Meaning and identity development thus appear to coincide and, as such, are jointly relevant to adolescents as they begin to engage in the process of self-definition and before they even reach the period of young adulthood.

Life meaning may be particularly salient to youth from immigrant backgrounds (e.g., adolescents who were foreign-born themselves and/or have parents who were foreign-born) above and beyond these normative patterns of development. For instance, immigrant families often exhibit some degree of social capital and resilience, perhaps purposefully seeking better opportunities or social and economic freedom (Suárez-Orozco and Suárez-Orozco 2001). Parents who have immigrated to the US may be striving for the "American Dream" and communicate to their children the value of working hard and achieving life goals (Horowitz 1983). Messages of success also may be passively transmitted as children witness opportunities resulting from their family's accomplishments. Such exposure to distinctive models of work and success may deepen the meaning in the lives of immigrant youth as they experience and assist in their family's progress.

As another example of why meaning in life may be particularly relevant to ethnically diverse youth, the broad literature on adversity and stress suggests that one method of coping that can lead to psychological growth is to make meaning out of difficult circumstances (Schaefer and Moos 1992). For instance, those who derive meaning from stress, trauma, or a life-threatening illness report healthier prognoses and better psychological well-being compared to those who do not engage in meaning-making (Taylor et al. 2000). Similarly, youth from ethnic minority backgrounds often struggle with finding their place in a European American majority, and may experience a unique set of stressors such as ethnic discrimination, language difficulties, or simply trying to fit in (Cooper et al. 2002; Garcia Coll and Magnusson 1997; Kessler et al. 1999). In coping with such challenges, some may adaptively develop a sense of meaning and, as a result, may then take proactive steps to end institutional discrimination and foster intergroup relations (Cross et al. 1998). Notably, not all youth experience such stressors, nor do all those who do cope in these ways. Hence, meaning-making experiences are just one way in which youth from ethnic minority backgrounds may be especially poised to develop a sense of purpose.

\section{Associations with Adolescent Adjustment}

The importance in studying purpose and meaning in adolescents is that these constructs have been positively linked with psychological and emotional health as well as with other indices of subjective well-being (e.g., "flow") (Czikszentmihalyi 1990; Ryff and Singer 1998; Zika and Chamberlain 1992). In adults, meaning has also been related to occupational success, since life meaning often is expressed through work or employment status (Ryff and Singer 1998). Logical parallels for adolescents are their academic attitudes and motivation. In fact, given that education is often viewed as one method by which to socially advance and achieve one's goals, academic motivation may be particularly salient to adolescents from ethnic minority families, for whom academic achievement could serve as a marker of success (Suárez-Orozco and Suárez-Orozco 2001). Hence, adolescent meaning in life may be not only associated with global indicators of adjustment (e.g., selfesteem) but also with outcomes within the academic arena (e.g., intrinsic motivation, academic enjoyment).

Meaning also may play a role in adolescents' day to day lives. Increasingly used in the stress and coping literature (e.g., Bolger and Zuckerman 1995; Almeida and Kessler 1998), the intense, repeated assessments made possible by daily diary methodology can provide rich and meaningful information regarding adolescents' daily well-being (e.g., positivity, distress). Daily reports also allow for the examination of emotional variability. Affective regulation research suggests that greater emotional lability is associated with problems such as depression and externalizing behavior (e.g., Silk et al. 2003), whereas greater stability in 
emotions can be viewed as a marker of positive well-being. Given the generally positive outcomes that meaning in life is thought to impart, perhaps meaning is related to average daily well-being as well as greater stability in daily wellbeing.

One essential consideration is whether presence versus search for meaning convey different associations with outcomes. Intuitively, presence of meaning can be expected to serve as a positive resource in adolescents' lives and relate to higher self-esteem, better academic adjustment, and more positive and stable daily well-being. However, links with search for meaning may be less obvious. Although the active process of searching or exploring can reflect an "approach" orientation which has been linked to adaptive outcomes (Carver and Scheier 1999), exploration may actually demand a difficult period of time. Erikson (1968) depicts youths' search for identity as a "crisis" characterized by intense turmoil and confusion. The search for life meaning can be seen as a comparable crisis and, as such, the exploration in achieving a successful resolution of this crisis may be associated with psychological distress. An interactive influence of presence and search may exist as well. For instance, youth who are discordant in their presence and search for meaning (e.g., lacking presence but searching) may experience less adaptive outcomes compared to those for whom presence and search for meaning correspond.

\section{Ethnic Identification and Meaning in Life}

Two theoretical perspectives point to social identification as a source of meaning in adolescents' lives. As stated earlier, Erikson's (1968) theory of psychosocial development describes adolescence as a critical period during which an understanding of one's life and life purpose emerges. Such an understanding actually results from the quintessential quest in establishing one's identity (Erikson 1968). Social identity theory (e.g., Tajfel 1981; Tajfel and Turner 1986) also supports links between identity and meaning, suggesting that feelings of connectedness and belonging to one's group motivate purposeful action in support of that group. For instance, ethnic identity has been linked to orientations toward familism and collectivism (Gaines et al. 1997; Kiang and Fuligni 2009). Social identification may thus enhance group attitudes, and provide opportunities for individuals to cultivate a deeper sense of purpose or meaning through their social relationships.

Particularly salient to youth from ethnic minority backgrounds, ethnic identity constitutes a primary domain of social identification. Analogous to our multidimensional conceptualization of presence and search for meaning, Phinney (1992) introduced two dimensions of ethnic identity. Ethnic belonging refers to one's ethnic pride and affiliation whereas ethnic exploration refers to the degree to which one actively explores one's ethnicity, traditions, and history. Considered a key construct in adolescents' lives, ethnic identity has been consistently linked with a variety of psychological, academic, and daily adjustment outcomes (e.g., Kiang et al. 2006; Umaña-Taylor 2004; Wong et al. 2003). However, the specific mechanism by which ethnic identity has such a positive influence remains unclear. Like ethnic identity, meaning in life has been reliably linked to positive adjustment (Ryff and Singer 1998); hence, perhaps meaning can account for the positive effects that are typically attributable to ethnic identity. That is, Eriksonian and social identity theories imply that ethnic identity is linked to a sense of meaning (e.g., through the process of identity development or through group connectedness). In turn, adolescents' sense of meaning could relate to a broad experience of eudaimonic well-being that pervades other areas of development and underlies associations between ethnic identity and outcomes.

\section{The Current Study}

We first examined group differences in presence and search for meaning and expected that, due to their cultural history, Latin and Asian American youth would report higher presence and search for meaning than European American youth. In addition, within each ethnic group, youth from the first generation were expected to report greater presence and search for meaning than those from subsequent generations. Since the establishment of and search for meaning reflect a process that should not theoretically affect males and females differently, differences by gender were explored but were not expected. Indeed, gender differences have not been found in either presence or search for meaning in prior work (Steger et al. 2006). We next anticipated that presence of meaning would be positively related to self-esteem, academic outcomes, daily well-being, and stability in daily emotionality. In line with Eriksonian notions of exploratory crisis, search for meaning was expected to relate to lower self-esteem and positivity, greater distress, and more fluctuation in daily emotional states. Interactive effects of presence and search for meaning also were explored. Consistent with theoretical perspectives on identity development, we also expected meaning to be associated with adolescents' ethnic identification. Third, in a series of mediational models, we expected meaning in life to account for a significant portion of the associations between ethnic identity and outcomes, which would provide evidence for meaning as a key linking mechanism to help explain the positive effects of ethnic identity. 


\section{Methods}

Participants

Twelfth grade students were recruited from three high schools in the Los Angeles metropolitan area. The first school consisted of predominantly Latin and Asian American students from families with lower-middle to middle class educational, occupational, and financial backgrounds, as described by the state (California Department of Education 2006). The second school consisted of mostly Latin American and European American students from families with lower-middle to middle class backgrounds. The third school included mostly middle to upper-middle class families from Asian and European American backgrounds. No single ethnicity dominated any of these schools; rather, the two largest ethnic groups each comprised $30-50 \%$ of each school's total population. Notably, each of the three schools reported similar drop-out rates that did not vary by ethnicity (California Department of Education 2006). All twelfth graders in two of the three schools and a random selection of approximately half of the twelfth graders in the third school were invited to participate because the large size of the third school made recruitment of the entire grade level not feasible.

Students from ethnic groups comprising too small a number for meaningful comparisons (e.g., Middle Eastern, African American, Multiethnic) were omitted (approximately $18 \%)$, resulting in a final sample of 579 (47\% male, 53\% female). Of this sample, $36 \%(n=208)$ had Latin American backgrounds, 44\% $(n=255)$ had Asian backgrounds, and 20\% ( $n=116$ ) had European (non-Hispanic) backgrounds. Within Latin and Asian ethnic categories, $85 \%$ of Latin Americans had Mexican ancestry and $70 \%$ of Asian Americans had Chinese ancestry. Other subgroups within these broader ethnic categories included Guatemalan, Honduran, Nicaraguan, Salvadoran, South Asian, Filipino, Japanese, Korean, Pacific Islander, Taiwanese, Thai, and Vietnamese. The majority of European American adolescents chose White as their primary ethnic label (90\%). Ethnic differences in parental education were found such that mothers of European American adolescents were most highly educated, followed by Asian American mothers and, lastly, Latin American mothers $(F(2,577)=39.34$, $p<.001)$. Latin American fathers were significantly less educated than Asian and European American fathers $(F$ (2, $577)=21.39, p<.001)$. Just over half of the adolescents were of the second generation $(53 \%)$, meaning that they were US-born and had at least one foreign-born parent. Approximately $22 \%$ were of the first generation (i.e., foreign-born), and $25 \%$ were of the third generation (i.e., USborn with US-born parents). Average age was 17.81 years $(\mathrm{SD}=.38)$, with a range of 16 to 19 years.
Procedure

Students who returned assent and parent consent forms completed a series of self-report questionnaires in smallgroup settings during school time. Questionnaires took approximately $30 \mathrm{~min}$ to complete and included purpose and meaning, ethnic identity, and general outcome measures. Upon completion of questionnaires, participants were given a packet of daily diary checklists as well as an electronic time stamper. Adolescents were instructed to complete one checklist each night for 14 consecutive nights, to seal each checklist in an envelope upon completion, and to stamp each seal with the time stamper. Time stampers recorded the current date and time and were programmed such that this information could not be altered. Research assistants returned at the end of the study period to collect all materials and to compensate adolescents for participation. Adolescents received $\$ 30$ cash for completing both the inschool questionnaires and daily diary components of the study. In addition, participants were told that they would receive two movie passes if inspection of daily materials suggested that reports were completed accurately (e.g., on time and correctly stamped). Virtually all of the diaries (96\%) were completed and $89 \%$ of the sample completed all 14 diaries. Of the completed diaries, $75 \%$ were completed on time, either on the correct night or before noon the next day. Consent forms were available in English, Spanish, and Chinese, developed through a series of translations and back-translations conducted by bilingual speakers. Although study materials were available in Spanish and Chinese, all students chose to complete measures in English.

\section{Measures}

\section{Meaning in Life}

The Meaning in Life Questionnaire (MLQ; Steger et al. 2006) was used to assess two dimensions of meaning. The Presence subscale consists of five items that reflect the degree to which individuals feel that their life is full of meaning. Sample items read, "I understand my life's meaning," and, "My life has a clear sense of purpose," The Search subscale consists of five items that reflect individuals' motivation and desire to find or deepen the meaning in their lives. Items are scored on a five-point Likert-type scale that range from 1 almost never to 5 almost always. Sample items read, "I am searching for my meaning in life," and, "I am looking for something that makes my life meaningful." Subscales were significantly correlated in the negative direction $(r=-.17, p<.001)$. The MLQ has been previously demonstrated as having good reliability, validity, and a stable factor structure (Steger et al. 2006). In the current study, reliabilities for Presence (Latin American: $\alpha=.84$; 
Asian American: $\alpha=.88$; European American: $\alpha=.91$ ) and Search (Latin American: $\alpha=.90$; Asian American: $\alpha=.87$; European American: $\alpha=.90$ ) were similar across ethnic groups.

\section{Ethnic Identity}

The Multigroup Ethnic Identity Measure (MEIM; Phinney 1992) was used to measure ethnic identity. The Ethnic Affirmation and Belonging subscale, consisting of five items, measures the extent to which students have positive feelings and feelings of connectedness toward their ethnic group. Sample items read, "I have a strong sense of belonging to my own ethnic group," "I am happy that I am a member of the group I belong to," and, "I feel good about my cultural or ethnic background." Internal consistencies were similar across all ethnic groups (Latin American: $\alpha=.87$; Asian American: $\alpha=.89$; European American: $\alpha=.92$ ). The Ethnic Identity Achievement subscale, consisting of seven items, assesses the extent to which individuals engage in an active exploration to learn more about their ethnic group. Sample items read, "I have spent time trying to find out more about my ethnic group, such as its history, traditions, and customs," "I think a lot about how my life will be affected by my ethnic group membership," and, "I have a clear sense of my ethnic background and what it means for me." This subscale also was reliable across ethnicity (Latin American: $\alpha=.77$; Asian: $\alpha=.83$; European: $\alpha=.80$ ). All items are scored on a 5-point scale ranging from "strongly disagree" to "strongly agree" with higher scores reflecting higher levels of Belonging and Exploration.

\section{Self-Esteem}

The Rosenberg Self-Esteem Scale (Rosenberg 1965), consisting of 10 items, was used to measure global self-esteem. Items are scored on a 5-point Likert-type scale that ranges from 1 strongly disagree to 5 strongly agree with higher scores reflecting higher self-esteem. Sample items read, "I feel that I have a number of good qualities," "I take a positive attitude toward myself," and, "I certainly feel useless at times" (reverse scored). Internal consistencies were similar across ethnicity (Latin American: $\alpha=.72$, Asian American: $\alpha=.69$; European American: $\alpha=.78$ ).

\section{Utility Value of School}

Adapted from research from Eccles (1983), and successfully used by Fuligni et al. (2005), the utility value of school was assessed by asking adolescents to report how important they think being in school is $(1=$ not at all important, $5=$ very important). Students were also asked how important they believe school is in their everyday life in terms of currently, for the future, and after graduating $(1=$ not at all important, $5=$ very important $)$. This scale was similarly reliable for the adolescents from all three ethnic backgrounds (Latin American: $\alpha=.78$, Asian American: $\alpha=$.74; European American: $\alpha=.79$ ).

\section{Value of Academic Success}

Value of academic success was assessed via a six-item scale adapted from Eccles (1983) that asks adolescents to place importance on succeeding and doing well in school. On a scale of 1 not important to 5 very important, students reported how important the following things are: "that you do well in school," "that you get good grades," "that you get an 'A' on almost every test," "that you go to college after high school," "that you be one of the best students in your class," "that you go to the best college after high school." Reliabilities were similar across ethnicity (Latin: $\alpha=.87$, Asian: $\alpha=.84$; European: $\alpha=.85$ ).

\section{Intrinsic Academic Motivation}

Students' intrinsic value of school was measured by asking students to respond to the following two items adapted from Eccles (1983): "In general, I find working on school work..." ( $1=$ very boring, $5=$ very interesting $)$, and "How much do you like working on school work?" $(1=a$ little, $5=a$ lot $)$. These two items were highly correlated across adolescents from all three ethnic backgrounds (Latin American: $r=.68$, Asian American: $r=.75$, European American: $r=.75)$.

\section{Daily Positivity and Daily Distress}

For 14 consecutive days, participants reported on a fivepoint Likert-type scale (range $=0-4$ ) the extent to which they felt each of three items for each subscale on each particular day (positivity: happy, joyful, calm; distress: sad, hopeless, discouraged). The positivity scale was modeled after the Profile of Moods States (POMS; Lorr and McNair 1971) whereas the distress scale was drawn directly from the POMS. Both have been used successfully in prior daily diary work (e.g., Kiang et al. 2006). Responses range from not at all to extremely with higher scores reflecting greater positivity and greater distress. Internal consistencies were averaged across each daily assessment and were similar across ethnicity for positivity (Latin American: $\alpha=.85$, Asian American: $\alpha=.83$; European American: $\alpha=.83$ ) and distress (Latin American: $\alpha=.76$, Asian American: $\alpha=.81$; European American: $\alpha=.82$ ). Daily reports were averaged across the study period to create overall indicators of daily happiness and distress. Deviation scores were 
calculated as each individual's daily deviation from his or her average levels of positivity and distress. We averaged the absolute values of daily deviation scores to create an index of adolescents' average daily variability in wellbeing.

\section{Socioeconomic Status}

As a demographic control for our mediational analyses, we created an index of socioeconomic status using adolescents' reports of their parents' education and occupation. Adolescents reported on the education level of their mothers and fathers on a six-point scale using the following response options: Elementary/junior high school, Some high school, Graduated from high school, Some college, Graduated from college, Graduated from law, medical, or graduate school. Adolescents also listed their parents' current job, if any. Responses were coded on a five-point scale using the following codes (sample occupations are reported in parentheses): Unskilled (housecleaning, parking attendant), Semi-skilled (cashier, waitress), Skilled (electrician, bank teller), Semi-professional (nurse, small business owner), Professional (engineer, physician). Socioeconomic status was computed using the mean of the standardized values of both parents' educational and occupational statuses.

\section{Results}

Structural Validity of the Meaning in Life Questionnaire (MLQ)

To address whether the originally proposed factor structure of the MLQ was consistent within our sample of ethnically diverse adolescents, we examined measurement invariance by ethnicity. We utilized group modeling techniques described by Jöreskog and Sörbom (1996) and specified models consisting of two latent variables: presence and search for meaning. Each latent variable was comprised of five items from the MLQ, as described by Steger et al. (2006). We compared the global Chi-square of two models: one in which MLQ factor loadings were free to vary among Latin, Asian, and European American adolescents, and another in which the loadings were constrained to be equal. The difference in Chi-square values between the free-tovary and constrained models was not significant at the $p<.001$ level $\left(\chi^{2}(3)=2.39\right)$, suggesting that the MLQ exhibits a factor structure that does not vary by ethnicity.

To further support the measurement equivalence of the MLQ across ethnic groups, we examined fit indices that were derived from a measurement model, with presence and search for meaning as two latent variables, based on data from our entire sample and data that were stratified by ethnicity. In line with procedures put forth by Hoyle and Panter (1995), we considered multiple indices of fit including the Comparative Fit Index (CFI) as an index of incremental fit, and the error-based Root Mean Square Error of Approximation (RMSEA). Although the $\chi^{2}$ goodness-offit was also examined, it should be noted that this statistic tends to be sensitive to sample size (Schumacker and Lomax 1996), which could skew our results. The following indices were obtained from the overall model with all participants included: $\left(\chi^{2}(34)=142.82, p<.001, \mathrm{CFI}=.97\right.$, RMSEA $=.08)$. Similar fit indices were found for ethnically-stratified measurement models, which corroborates findings from group modeling techniques and provides additional support for the measurement invariance of the MLQ [Latinos: $\chi^{2}(34)=116.10, p<.001$, CFI $=.95$, RMSEA $=.10$; Asians: $\chi^{2}(34)=70.85, p<.001, \mathrm{CFI}=$ .98, RMSEA $=.06$; Europeans: $\chi^{2}(34)=79.15, p<.001$, $\mathrm{CFI}=.96, \mathrm{RMSEA}=.10]$.

\section{Group Differences in Meaning}

Ethnicity and gender were entered as independent variables in two separate ANOVAs predicting presence of and search for meaning. As shown in Table 1, an overall effect of ethnicity on presence of meaning was found such that Latin Americans reported the highest levels of presence of meaning, European Americans reported lowest, and Asian Americans reported levels in between $(F(2,577)=3.06$, $p<.05)$. However, Bonferroni post-hoc tests revealed that specific group contrasts were only marginally significant $(p=.11-.17)$. No main effects of gender and no gender by ethnicity interactions were found.

A main effect of ethnicity also was found for search for meaning $(F(2,577)=10.14, p<.001)$. Bonferroni tests revealed that adolescents from Asian American backgrounds reported significantly higher levels of search compared to both Latin $(p<.001)$ and European American adolescents $(p<.01)$. There were no significant gender differences, but a gender by ethnicity interaction emerged $(F(2,577)=3.07$, $p<.05)$ such that Latin American females reported lower search for meaning $(M=2.91, \mathrm{SD}=.96)$ compared to Latin American males $(M=3.17, \mathrm{SD}=1.04)$, whereas females from Asian $(M=3.49, \mathrm{SD}=.97)$ and European $(M=3.13, \mathrm{SD}=.91)$ backgrounds reported higher search compared to their male counterparts (Asian: $M=3.33$, $\mathrm{SD}=1.00$; European: $M=2.95, \mathrm{SD}=1.12$ ).

Given confounds between ethnicity and generational status, which resulted in low numbers of students in certain ethnicity by generation subgroups, generational differences were first examined using within-ethnicity ANOVAs. Generational differences were not significant for any of the three ethnic groups ( $F$ range $=.59-1.59$, ns). To further explore interactive effects between generation and other 
Table 1 Mean (SD) levels of meaning in life by ethnicity and gender

\begin{tabular}{llllll}
\hline & Ethnicity & & & \multicolumn{2}{c}{ Gender } \\
\cline { 2 - 4 } \cline { 5 - 6 } & Latin & Asian & European & & Male \\
\hline Presence of meaning & $3.44(.87)$ & $3.27(.93)$ & $3.21(.99)$ & $3.30(.98)$ & $3.34(.87)$ \\
Search for meaning & $3.02_{\mathrm{b}}(1.00)$ & $3.41_{\mathrm{a}}(.99)$ & $3.05_{\mathrm{b}}(1.01)$ & $3.20(1.04)$ & $3.19(.99)$ \\
\hline
\end{tabular}

Different subscripts reflect Bonferroni differences significant at $p<.01$

$(N=579)$

demographic variables, we examined two additional ANOVAs with ethnicity, gender, and generation as the independent variables and presence and search for meaning as the dependent variables. Results similarly suggested that generation did not have any main or interactive effects with ethnicity or gender on either presence or search for meaning.

Associations Between Meaning and Ethnic Identity Subscales and Adolescent Adjustment

As shown in Table 2, presence of meaning was related to more optimal outcomes such as self-esteem and positive attitudes toward school. Specifically, adolescents with greater presence of meaning appreciated the intrinsic utility and value of education, and were more intrinsically motivated to perform academically well. Daily emotionality also was correlated with presence of meaning such that those with greater presence reported greater daily happiness, less daily distress, and less fluctuation in their daily distress.

Correlations between search for meaning and adjustment generally support Eriksonian notions regarding the psychological difficulty of exploration. For instance, adolescents who reported greater search for meaning reported lower self-esteem, less daily happiness, and more daily distress. Greater deviation in daily happiness and distress, or greater emotional lability, also was associated with search for meaning. Of the three academic outcomes, only a small positive correlation was found between search for meaning and the valuing of academic success.

To examine interactive effects of presence and search for meaning, the two variables and an interaction term were entered in a series of regressions predicting adjustment. None of the interactions were significant suggesting that the effect of one dimension of meaning does not vary according to the other dimension.

Significant associations also were found between ethnic identity subscales and adjustment. In line with prior research supporting the positive benefits of ethnic identity, higher levels of ethnic belonging and exploration were significantly correlated with better academic adjustment and higher daily happiness. Ethnic belonging was further associated with higher self-esteem, less daily distress, and more variation in daily happiness.

\section{Associations Between Meaning and Ethnic Identity}

As shown in Table 3, presence of meaning was significantly correlated with both dimensions of ethnic identity such that those who felt more positively about their ethnic group and those who reported greater ethnic exploration reported higher levels of meaning. Notably, ethnic identity was not significantly associated with search for meaning. Interactive effects of presence and search for meaning on ethnic identity dimensions were not found.

Presence of Meaning as a Mediator of Associations Between Ethnic Identity and Adjustment

To examine the significance of meaning in life as a mediator of ethnic identity and adjustment, we utilized several techniques outlined in recent work (MacKinnon et al. 2002). First, we established the necessary conditions to examine mediation as traditionally outlined by Baron and Kenny (1986) (e.g., significant associations between

Table 2 Correlations among meaning and ethnic identity subscales and adjustment

\begin{tabular}{|c|c|c|c|c|c|c|c|c|}
\hline & Self-esteem & Acad. utility & Acad. value & Intrinsic motiv. & Daily happy & Daily distress & Deviate- happy & Deviate- distress \\
\hline Presence-meaning & $.41 * * *$ & $.27 * * *$ & $.25^{* * *}$ & $.32 * * *$ & $.30 * * *$ & $-.20 * * *$ & .03 & $-.11 *$ \\
\hline Search-meaning & $-.22 * * *$ & $.08^{\dagger}$ & $.12 * *$ & -.05 & $-.14 * * *$ & $.20 * * *$ & $.10 *$ & $.18 * * *$ \\
\hline Ethnic belonging & $.29 * * *$ & $.25^{* * *}$ & $.20 * * *$ & $.18 * * *$ & $.27 * * *$ & $-.15 * * *$ & $.13 * *$ & -.06 \\
\hline Ethnic exploration & .06 & $.23 * * *$ & $.21 * * *$ & $.23 * * *$ & $.15 * * *$ & .02 & $.08^{\dagger}$ & .04 \\
\hline
\end{tabular}

${ }^{\dagger} p<.10, * p<.05, * * p<.01, * * * p<.001$ 
Table 3 Correlations among meaning and ethnic identity subscales

(1)

(2)

(3)

(4)

(1) Presence-meaning

(2) Search-meaning

(3) Ethnic belonging

(4) Ethnic exploration

$* * * p<.001$

the initial variables, the mediator, and outcomes). Next, we utilized Sobel tests to determine the statistical significance of the actual mediating effect. As outlined by MacKinnon et al. (2002), Sobel tests are among the several recommended tests that most accurately evaluate and detect the presence of mediation.

Results shown in Tables 2 and 3 suggest that conditions for mediation were indeed met. Given that ethnic belonging was more strongly and consistently associated with adjustment outcomes compared to ethnic exploration, we focused on mediating the initial effect of belonging. In addition, compared to search for meaning, presence of meaning was more strongly associated with both ethnic belonging and adolescent adjustment; hence, presence of meaning was examined as the key mediator. Given the relatively weaker bivariate associations between ethnic belonging, presence of meaning, and daily emotional variation, we concentrated on outcomes of self-esteem, academic utility and value, academic motivation, and average levels of daily happiness and distress. In our mediational models, ethnicity, gender, and an index of socioeconomic status were included in Step 1 as controls given that prior work has documented such demographic differences in psychological and academic adjustment (DuBois et al. 2002; Fuligni et al. 2005).

As shown in Table 4, after accounting for ethnicity, gender, and socioeconomic status, ethnic belonging was significantly associated with all indicators of adjustment. Associations were in expected directions such that a stronger sense of connectedness and affiliation with one's ethnic group was related to higher self-esteem, higher attitudes toward the utility and value of education, higher intrinsic motivation, higher average levels of daily happiness, and lower daily distress. When presence of meaning was accounted for at Step 2, all of the prior effects of ethnic belonging significantly decreased in magnitude. Approximately $34 \%$ of the initial effect of ethnic belonging on selfesteem was accounted for by youth meaning in life. In terms of academic outcomes, meaning accounted for $29 \%$ of the association between ethnic belonging and academic utility, $33 \%$ of the association with academic value, and $64 \%$ of the association with intrinsic motivation. Presence of meaning also mediated the association between ethnic belonging and daily well-being, accounting for $25 \%$ of the initial association with daily happiness and $46 \%$ of the association with daily distress. Sobel tests of the significance of mediation confirmed that presence of meaning

Table 4 Presence of meaning as a mediator of ethnic identity and outcomes

\begin{tabular}{|c|c|c|c|c|c|c|c|c|c|c|c|c|c|c|c|c|c|c|}
\hline & \multicolumn{3}{|c|}{ Self-esteem } & \multicolumn{3}{|c|}{ Acad. utility } & \multicolumn{3}{|c|}{ Acad. value } & \multicolumn{3}{|c|}{ Intrinsic motiv. } & \multicolumn{3}{|c|}{ Daily happy } & \multicolumn{3}{|c|}{ Daily distress } \\
\hline & $b$ & SE & $\beta$ & $b$ & SE & $\beta$ & $b$ & SE & $\beta$ & $b$ & $\mathrm{SE}$ & $\beta$ & $b$ & SE & $\beta$ & $b$ & $\mathrm{SE}$ & $\beta$ \\
\hline \multicolumn{19}{|l|}{ Step 1} \\
\hline SES & .01 & .04 & .01 & -.11 & .04 & $-.11 *$ & -.02 & .04 & -.02 & -.14 & .05 & $-.12 * *$ & -.04 & .04 & -.04 & -.01 & .03 & -.02 \\
\hline Latin Am. & -.26 & .09 & $-.17 * *$ & .18 & .10 & $.11^{\dagger}$ & .07 & .10 & .05 & .17 & .12 & .08 & -.13 & .10 & -.09 & -.10 & .07 & -.09 \\
\hline Asian Am. & -.36 & .08 & $-.24 * * *$ & .25 & .09 & $.15^{* *}$ & .21 & .09 & $.14 *$ & .14 & .11 & .07 & -.21 & .09 & $-.14 *$ & .02 & .06 & .02 \\
\hline Gender & -.10 & .06 & $-.07^{\dagger}$ & .04 & .06 & .02 & .06 & .06 & .04 & .13 & .08 & $.07^{\dagger}$ & -.01 & .06 & -.01 & .15 & .05 & $.15^{* * * *}$ \\
\hline Eth. belong. & .26 & .03 & $.32 * * *$ & .19 & .04 & $.21 * * *$ & .17 & .04 & $.20 * * *$ & .15 & .05 & $.14 * * *$ & .23 & .04 & $.28 * * *$ & -.07 & .03 & $-.13 * *$ \\
\hline \multicolumn{19}{|l|}{ Step 2} \\
\hline SES & .00 & .04 & .00 & -.11 & .04 & $-.12 * *$ & -.02 & .04 & -.02 & -.15 & .05 & $-.12 * *$ & -.05 & .04 & -.05 & -.01 & .03 & -.01 \\
\hline Latin Am. & -.27 & .09 & $-.17 * *$ & .18 & .10 & $.11^{\dagger}$ & .07 & .10 & .04 & .16 & .12 & .08 & -.13 & .10 & -.09 & -.10 & .07 & -.09 \\
\hline Asian Am. & -.36 & .08 & $-.24 * * *$ & .25 & .09 & $.16^{* *}$ & .22 & .09 & $.14 *$ & .15 & .11 & .08 & -.19 & .08 & $-.13 *$ & -.02 & .06 & .01 \\
\hline Gender & -.10 & .06 & $-.07^{\dagger}$ & .04 & .06 & .02 & .06 & .06 & .04 & .13 & .08 & $.07^{\dagger}$ & -.02 & .06 & -.01 & .16 & .04 & $.15 * * *$ \\
\hline Eth. belong. & .17 & .03 & $.21 * * *$ & .13 & .04 & $.15 * * *$ & .11 & .04 & $.13 * *$ & .06 & .05 & .05 & .17 & .04 & $.21 * * *$ & -.04 & .03 & -.07 \\
\hline Presence & .28 & .03 & $.35 * * *$ & .18 & .04 & $.21 * * *$ & .18 & .04 & $.21 * * *$ & .30 & .04 & $.28 * * *$ & .19 & .04 & $.23 * * *$ & -.10 & .03 & $-.17 * * *$ \\
\hline
\end{tabular}

Note: Ethnicity was dummy coded with European Americans as the reference group. Interactions between ethnicity and the mediator were examined but omitted since no interactions were significant. Effect sizes were as follows: Self-Esteem: $R^{2}=.12$ for Step $1, \Delta R^{2}=.11$ for Step 2 $(p<.001)$; Utility: $R^{2}=.09$ for Step $1, \Delta R^{2}=.04$ for Step $2(p<.001)$; Value: $R^{2}=.05$ for Step $1, \Delta R^{2}=.04$ for Step $2(p<.001)$; Intrinsic: $R^{2}=.06$ for Step $1, \Delta R^{2}=.07$ for Step $2(p<.001)$; Happiness: $R^{2}=.09$ for Step $1, \Delta R^{2}=.05$ for Step $2(p<.001)$; Distress: $R^{2}=.05$ for Step $1, \Delta R^{2}=.03$ for Step $2(p<.001)$

${ }^{\dagger} p<.10, * p<.05, * * p<.01, * * * p<.001$ 
was a statistically significant mediator of all of the initially observed associations between ethnic belonging and adolescent adjustment $(Z$ range $=3.08-6.07, p<.01)$.

\section{Alternative Mediation Models}

The meditational models tested above were strongly grounded in theory. Nonetheless, we examined the possibility that ethnic identity serves as a mediator between meaning in life and adjustment. We conducted a series of multiple regressions with demographic controls and the initial effect of presence of meaning entered at Step 1, and ethnic belonging entered as a mediator at Step 2. Although the effects of meaning decreased slightly once ethnic belonging was taken into account, the magnitudes of the decreases were not striking. Ethnic belonging only explained $7-21 \%$ of the initial effects of meaning on adjustment. In contrast, as described above, meaning in life explained 25-64\% of the initial effect of ethnic belonging. These results provide support that meaning life mediates ethnic belonging, rather than vice versa.

\section{Discussion}

Establishing a sense of purpose and meaning in life is an important developmental task, as these constructs have been described as indicators of eudaimonic well-being with significant implications for individuals' adjustment (Deci and Ryan 2000; Ryff and Singer 1998). The goal of the current research was to provide an in-depth examination of life meaning, building on existing work by specifically focusing on adolescents from ethnically diverse backgrounds. We examined group differences in meaning, how meaning relates to adolescents' general, academic, and daily wellbeing, whether meaning can be linked to adolescents' ethnic identification, and whether the construct serves as a key mediator to help explain positive associations between ethnic identity and adjustment.

Although demographic differences were not as robust as expected, ethnic variation in meaning in life supports the utility of further examining this construct across diverse groups. Marginally significant group differences in presence of meaning suggested that youth from Latin and Asian American backgrounds generally report higher levels of presence than those from European American backgrounds. With respect to search for meaning, adolescents from Asian American backgrounds reported significantly higher exploration compared to both Latin and European American adolescents.

Several explanations can be put forth as to why such ethnic variation was found. One is that having an ethnic minority background presents unique experiences and social challenges that adolescents must face and ultimately derive meaning from. For instance, those who are in the ethnic minority must often cope with prejudice or discrimination (Phinney 1996; Kessler et al. 1999), and may develop a sense of meaning as an adaptive result of trying to understand such experiences. This process could parallel the phenomenon of meaning-making in the face of adverse situations (Schaefer and Moos 1992). However, although our interpretations allude to the idea that acculturation and stress (e.g., discrimination) may create experiences from which meaning-making can occur, future work should explicitly examine these topics in greater detail.

Adolescents' cultural histories could serve as an additional explanation for ethnic group differences in meaning. Adolescents from Asian and Latin American families may be working to help their families attain success in America, and thus value the importance of making and achieving personal and familial goals. Perhaps such aspirations have prompted these youth to think deeply about and actively ascribe a sense of meaning to their lives. Interestingly, although no generational differences were significant, trends were in expected directions such that meaning in life was higher in adolescents from families with more recent immigrant histories.

In terms of gender, similar to prior research on mostly European American samples (Steger et al. 2006), gender differences were not found for either dimension of purpose and meaning. However, one gender by ethnicity interaction was found whereby Latin American females reported lower levels of search for meaning than Latin American males, while Asian and European American females reported higher search for meaning than their male counterparts. Cultural considerations and socialization differences in terms of gender role expectations could be implicated in this finding, but additional research is needed to better disentangle these effects.

The importance of understanding adolescent meaning in life rests in this construct having wide-reaching associations with adjustment, extending the existing literature that supports the importance of meaning in predominantly European American and adult samples (Steger et al. 2006). Presence of meaning, in particular, was linked to positive indicators of development such that adolescents who perceived that their lives were more meaningful reported higher self-esteem, more positive academic attitudes, and greater intrinsic motivation. These positive effects also were infused into adolescents' daily lives such that greater meaning was associated with higher levels of average daily happiness and lower daily distress, as well as with greater emotional stability. It thus appears that a variety of positive outcomes can stem from having a clear sense of the meaning that underlies one's life, supporting the idea that meaning in life constitutes one dimension of eudaimonic 
well-being that pervades multiple aspects of development (Ryff and Singer 1998).

In contrast, adolescents who are actively engaged in a search for meaning report less ideal outcomes. Rather, an active search or exploration for meaning appears to resemble an Eriksonian "crisis" (Erikson 1968; Marcia 1966). Aside from a relatively small, positive association with the valuing of academic success, adolescents who reported that they are currently searching for their life purpose also reported lower self-esteem, lower daily happiness, greater daily distress, and greater emotional lability at the daily level. Associations with daily variation in emotions are particularly noteworthy given that prior work has linked emotional instability with a number of problematic outcomes such as depression (Silk et al. 2003). Taken together, our findings suggest that search for meaning constitutes a perturbation that may be essentially normative and perhaps even necessary in order to achieve an ultimate sense of meaning. Once achieved, presence of meaning can then have a positive and extensive effect on diverse developmental outcomes.

In terms of one way in which meaning in life may be conceived, Erikson's (1968) theory of identity development has long advocated that purpose and meaning emerge from the successful resolution of the identity crisis that occurs during adolescence. Social identity theorists (e.g., Tajfel 1981) also contend that group identity is deeply linked with life purpose via the opportunity to have a meaningful role in maintaining and promoting the wellbeing of one's social relationships and social group. Significant correlations between ethnic identity and presence of meaning empirically support these theoretical notions. As theory would suggest, a sense of ethnic identity or group connectedness appears to be one mechanism by which adolescents come to derive a deeper understanding of their life meaning.

In turn, a sense of meaning was found to mediate the positive effect of ethnic identity, specifically, ethnic belonging on psychological, academic, and daily outcomes. Although prior work has consistently documented positive links between ethnic identity and adjustment (e.g., Fuligni et al. 2005; Umaña-Taylor 2004), it has yet to be entirely clear why ethnic identity has such a beneficial effect. Indeed, an important task for contemporary research is to identify the precise mechanisms by which ethnic identity has such a positive impact on development (Kiang et al. 2006). Our data pinpoint meaning in life as one explanatory variable. That is, our results suggest that a strong sense of ethnic identification conveys a sense meaning, which then contributes to greater self-esteem, more positive academic attitudes and motivation, and more adaptive daily well-being. Even after controlling for important demographic variables, presence of meaning explained between
25 and $64 \%$ of the initial effect of ethnic belonging on outcomes, supporting the idea that adolescents' sense of meaning in life represents one reason why positive associations may be found between ethnic identity and adjustment. Notably, meaning only accounted for a portion of the robust effect of ethnic belonging. To be sure, additional mediational variables are likely to exist.

One limitation to this study was that our analyses were correlational in nature. Although significant and expected effects were found, it would be fruitful for future research to utilize longitudinal data to more definitely predict associations between meaning, social identity, and adjustment. Results from alternative meditational models, which were not as robust, provide further support for the theoretical directionality of the primary models examined, but multiple points of data are necessary to establish true mediational effects and to more confidently assert that ethnic identity contributes to meaning which, in turn, contributes to positive outcomes over time. Continuing to examine processes of meaning in longitudinal samples could also speak to some of our findings that were rather unexpected. For instance, search for meaning appeared to be orthogonal to the search for a greater understanding of one's ethnic background, as search for meaning was not strongly associated with either ethnic belonging or ethnic exploration. One explanation is that search for meaning may reflect a rather broad phenomenon and, as such, may be associated with a variety of factors above and beyond ethnic identity (e.g., religious identity, social relationships). Developmentally, it also is possible that constructs of ethnic identity and search for meaning are indeed related, but their association does not emerge until later in development or over a longer period of time. Additional research would be needed to determine whether these constructs continue to operate independently or whether, over time or during different developmental periods, they are more intricately tied.

Another caveat to the current study was that we focused on students in the twelfth grade since constructs of meaning may be particularly salient to these adolescents who are likely faced with the issue of where their life is headed after their last year of high school. It would be important to replicate our findings in younger samples to determine how early in development meaning evolves and in older samples to determine whether these processes are similar later in life. Furthermore, because we focused on seniors in high school, it is possible that our sample was not representative of all adolescents but rather those who choose to remain in school. Future research utilizing more diverse samples (e.g., adolescents who are not enrolled in school) would be needed to increase the generalizability of our findings. In addition, although our Latin American and Asian samples were largely Mexican and Chinese, respectively, over $20 \%$ 
of adolescents from ethnic minority backgrounds were diverse in their subethnic heritage. Hence, future work should continue utilizing ethnically-rich samples to enhance generalizability to diverse youth.

Another suggestion for future research is to examine associations between meaning and additional domains of social identification. Although ethnic identity is applicable to all individuals (Phinney 1996), it is possible that ethnic group membership is more salient for those from ethnic minority backgrounds. Hence, for European Americans in particular, perhaps ethnic identity is not as central as other social domains in which individuals can identify. Indeed, prior research suggests that, even for those from ethnic minority backgrounds, ethnic identity is only one of many group identities that have the potential to influence development (Cross and Fhagen-Smith 2001). Other identity domains, such as religious identity or even family identity, may provide an equal or even greater sense of meaning in adolescents' lives. Further exploration into the joint resources that social identification and meaning provide to adolescents may be helpful in optimizing their development, especially in light of youth from diverse cultural backgrounds.

Yet, our results suggest that, despite ethnic group differences in average levels of meaning in life, adolescents' life meaning played a critical role in their development regardless of ethnic background. An adolescent thus may appear to exhibit the following pattern. He or she feels a strong sense of belonging and connectedness with his or her ethnic group. Accomplishing this developmental goal of social or group identification then leads the individual to better understand where he or she fits in society and in terms of his or her social roles, perhaps providing a broad sense of what the deeper meaning in his or her life might be. Having a strong sense of group membership also may motivate the individual to actively participate in the betterment of his or her social group, and provide opportunities to have a purposeful role in his or her group relationships. These feelings of purpose and meaning may then permeate into other arenas in life and provide a general sense of positivity and well-being that translates into better psychological adjustment, daily adjustment, and a greater motivation to do well in areas where purpose and goals are important (e.g., career or educational advancement).

By illuminating an additional step in the link between ethnic identity and well-being, we can broaden opportunities to potentially intervene and promote adolescent health. For instance, our results suggest that one way to enhance adolescents' meaning in life, and ultimately their adjustment, is to provide cultural support and to encourage adolescents' connection with their ethnic group. Indeed, fostering ethnic identity with an eye towards promoting adolescents' deeper sense of meaning in life could perhaps provide the most favorable outcomes, both psychologically and academically. As a natural consequence of the developmental period of adolescence, many youth struggle with figuring out who they are and what their life has in store for them. Although adolescence is a period that is potentially ridden with angst, discovering ways to help adolescents successfully navigate through this delicate transition and in due course establish a sense of meaning can help pave the way towards healthy developmental outcomes.

Open Access This article is distributed under the terms of the Creative Commons Attribution Noncommercial License which permits any noncommercial use, distribution, and reproduction in any medium, provided the original author(s) and source are credited.

\section{References}

Almeida, D. M., \& Kessler, R. C. (1998). Everyday stressors and gender differences in daily distress. Journal of Personality and Social Psychology, 75, 670-680.

Baron, R. M., \& Kenny, D. A. (1986). The moderator-mediator variable distinction in social psychological research: Conceptual, strategic, and statistical considerations. Journal of Personality and Social Psychology, 51, 1173-1182.

Bolger, N., \& Zuckerman, A. (1995). A framework for studying personality in the stress process. Journal of Personality and Social Psychology, 69, 890-902.

California Department of Education. (2006). School summary data. Retrieved January 27, 2006, from http://dq.cde.ca.gov/dataquest/.

Carver, C. S., \& Scheier, M. F. (1999). Stress, coping, and selfregulatory processes. In L. A. Pervin \& O. P. John (Eds.), Handbook of personality: Theory and research (2nd ed.). New York: Guilford.

Cooper, C. R., Cooper, R. G., Azmitia, M., Chavira, G., \& Gullatt, Y. (2002). Bridging multiple worlds: How African American and Latino youth in academic outreach programs navigate math pathways to college. Applied Developmental Science, 6, 73-87.

Cross, W. E., Jr., \& Fhagen-Smith, P. (2001). Patterns of African American identity development: A life span perspective. In C. L. Wijeyesinghe \& B. W. Jackson III (Eds.), New perspectives on racial identity development: A theoretical and practical anthology (pp. 243-270). New York: New York University Press.

Cross, W. E., Jr., Parham, T. A., \& Helms, J. E. (1998). Nigrescence revisited: Theory and research. In R. L. Jones (Ed.), African American identity development: Theory, research, and intervention (pp. 3-72). Hampton, VA: Cobb and Henry.

Czikszentmihalyi, M. (1990). Flow: The psychology of optimal experience. New York: Harper and Row.

Damon, W., Menon, J., \& Bronk, K. C. (2003). The development of purpose during adolescence. Applied Developmental Science, 7, 119-128.

Deci, E. L., \& Ryan, R. M. (2000). The "what" and "why" of goal pursuits: Human needs and the self-determination of behavior. Psychological Inquiry, 11, 227-268.

DuBois, D. L., Burk-Braxton, C., Swenson, L. P., Tevendale, H. D., \& Hardesty, J. L. (2002). Race and gender influences on adjustment in early adolescence: Investigation of an integrative model. Child Development, 73, 1573-1592.

Eccles, J. S. (1983). Expectancies, values, and academic behaviors. In J. T. Spence (Ed.), Achievement and achievement motivation (pp. 75-146). San Francisco, CA: Freeman. 
Emmons, R. (1999). The psychology of ultimate concerns: Motivation and spirituality in personality. New York: Guilford.

Erikson, E. H. (1968). Identity: Youth and crisis. New York: Norton.

Fuligni, A. J., Witkow, M. R., \& Garcia, C. (2005). Ethnic identity and the academic adjustment of adolescents from Mexican, Chinese, and European backgrounds. Developmental Psychology, 41, 799-811.

Gaines, S. O., Marelich, W. D., Bledsoe, K. L., Steers, W. H., Henderson, M. C., Granrose, C. S., et al. (1997). Links between race/ethnicity and cultural values as mediated by racial/ethnic identity and moderated by gender. Journal of Personality and Social Psychology, 72, 1460-1476.

Garcia Coll, C., \& Magnusson, K. (1997). The psychological experience of immigration: A developmental perspective. In A. Booth, A. C. Crouter, \& N. S. Landale (Eds.), Immigration and the family: Research and policy on U.S immigrants (pp. 91131). Hillsdale, NJ: Lawrence Erlbaum.

Horowitz, R. (1983). Honor and the American dream: Culture and identity in a Chicano community. New Brunswick, NJ: Rutgers University Press.

Hoyle, R. H., \& Panter, A. T. (1995). Writing about structural equation models. In R. H. Hoyle (Ed.), Structural equation modeling: Concepts, issues, and applications (pp. 158-176). Thousand Oaks, CA: Sage.

Jöreskog, K., \& Sörbom, D. (1996). LISREL8: Structural equation modeling with the SIMPLIS command language. Hillsdate, $\mathrm{NJ}$ : Erlbaum

Kessler, R. C., Mickelson, K. D., \& Williams, D. R. (1999). The prevalence, distribution, and mental health correlates of perceived discrimination in the United States. Journal of Health and Social Behavior, 40, 208-230.

Kiang, L., \& Fuligni, A. J. (2009). Ethnic identity and family processes in adolescents with Latin American, Asian, and European backgrounds. Journal of Youth and Adolescence, 38, 228-241.

Kiang, L., Yip, T., Gonzales-Backen, M., Witkow, M. R., \& Fuligni, A. J. (2006). Ethnic identity and the daily psychological wellbeing of adolescents from Mexican and Chinese Backgrounds. Child Development, 77, 1338-1350.

Lorr, M., \& McNair, D. М. (1971). The profile of mood states manual. San Francisco, CA: Educational and Industrial Testing Service.

MacKinnon, D. P., Lockwood, C. M., Hoffman, J. M., West, S. G., \& Sheets, V. (2002). A comparison of methods to test mediation and other intervening variable effects. Psychological Methods, 7 , $83-104$

Marcia, J. E. (1966). Development and validation of ego-identity status. Journal of Personality and Social Psychology, 3, 551-558.

Phinney, J. S. (1992). The multigroup ethnic identity measure: A new scale for use with diverse groups. Journal of Adolescent Research, 7, 156-176.

Phinney, J. S. (1996). When we talk about American ethnic groups, what do we mean? American Psychology, 9, 918-927.

Rosenberg, M. (1965). Society and the adolescent self-image. Princeton, NJ: Princeton University Press.

Ryan, R. M., \& Deci, E. L. (2001). On happiness and human potentials: A review of research on hedonic and eudaimonic well-being. Annual Review of Psychology, 52, 141-166.
Ryff, C. D. (1989). Happiness is everything, or is it? Explorations on the meaning of psychological well-being. Journal of Personality and Social Psychology, 57, 1069-1081.

Ryff, C. D. (1995). Psychological well-being in adult life. Current Directions in Psychological Science, 4, 99-104.

Ryff, C. D., \& Singer, B. (1998). The contours of positive human health. Psychological Inquiry, 9, 1-28.

Schaefer, J. A., \& Moos, R. H. (1992). Life crises and personal growth. In B. N. Carpenter (Ed.), Personal coping: Theory, research, and application (pp. 149-170). Westport, CT: Praeger Publishers/Greenwood Publishing Group.

Schumacker, R. E., \& Lomax, R. G. (1996). A beginner's guide to structural equation modeling. Mahwah, NJ: Erlbaum Associates.

Silk, J. S., Steinberg, L., \& Morris, A. S. (2003). Adolescents' emotion regulation in daily life: Links to depressive symptoms and problem behavior. Child Development, 74, 1869-1880.

Steger, M. F., Frazier, P., Oishi, S., \& Kaler, M. (2006). The meaning in life questionnaire: Assessing the presence of and search for meaning in life. Journal of Counseling Psychology, 53, 80-93.

Suárez-Orozco, C., \& Suárez-Orozco, M. M. (2001). Children of immigration. Cambridge, MA: Harvard University Press.

Tajfel, H. (1981). Human groups and social categories: Studies in social psychology. Cambridge: Cambridge University Press.

Tajfel, H., \& Turner, J. C. (1986). The social identity theory of intergroup behavior. In S. Worchen \& W. G. Austin (Eds.), Psychology of intergroup relations (pp. 7-24). Chicago: Nelson Hall.

Taylor, S. E., Kemeny, M. E., Reed, G. M., Bower, J. E., \& Gruenewald, T. L. (2000). Psychological resources, positive illusions, and health. American Psychologist, 55, 99-109.

Umaña-Taylor, A. J. (2004). Ethnic identity and self-esteem: Examining the role of social context. Journal of Adolescence, 27, 139-146.

Wong, C. A., Eccles, J. S., \& Sameroff, A. (2003). The influence of ethnic discrimination and ethnic identification on African American adolescents' school and socioemotional adjustment. Journal of Personality, 71, 1197-1232.

Zika, S., \& Chamberlain, K. (1992). On the relation between meaning in life and psychological well-being. British Journal of Psychology, 83, 133-145.

\section{Author Biographies}

Lisa Kiang is Assistant Professor of Psychology at Wake Forest University. Her area of research is in cultural identity and social relationships, with an emphasis on positive well-being in ethnically diverse adolescents.

Andrew J. Fuligni is Professor of Psychology and Psychiatry at the University of California, Los Angeles. Dr. Fuligni's research has focused on family relationships and adolescent development among culturally and ethnically diverse populations. 